\title{
ANALISA DAN PERANCANGAN DIGITALISASI DOKUMEN SURAT DAN AGENDA Pada Kantor Kepala DESA CIKOLELET
}

\author{
Hendra Mayatopani, Wahyu Tisno Atmojo ${ }^{2}$, Erick Dazki ${ }^{3}$ \\ ${ }^{123}$ Universitas Pradita Program studi Sistem Informasi Scientia Business Park, Jl. Gading Serpong Boulevard \\ No.1, Curug Sangereng, Kelapa Dua, Tangerang, Banten 15810 \\ mayatopani@gmail.com,wahyu.tisno@pradita.ac.id, erick.dazki@pradita.ac.id
}

\begin{abstract}
Abstrak
Desa Cikolelet merupakan desa wisata yang terletak di Kabupaten Cinangka, Jawa Barat. Desa ini telah ditetapkan pada akhir 2018 oleh Bupati Serang menjadi yang pertama sebagai Desa wisata di Kabupaten Serang. Untuk menunjang pengarsipan yang dilakukan oleh kepala desa yang pada saat ini pegelolaan data surat meliputi (surat tugas, surat kerjasama, surat pengumuman dan surat lainnya) serta agenda meliputi(bulan dan tahun) belum terdapatnya proses digitalisasi dokumen yang dilakukan tersistem sehingga manajemen berkas pada surat tidak terorganisir. Oleh karena itu dalam memberikan kontribusi pengembangan sistem informasi kepada desa Cikolelet perihal penerapan digitalisasi dokumen surat dan agenda yang merupakan faktor penting dalam organisasi baik instansi pemerintah ataupun swasta, dalam mendukung dan meningkatkan kinerja kepala desa dalam hal informasi surat dan agenda oleh karena itu penggunaan pemanfaatan aplikasi sistem yang akan membantu dalam kegiatan mengelola dokumen mengenai surat dan agenda agar terdapatnya pengaman dokumen fisik hasil cetak dan pencarian lebih mudah dilakukan. Pada penelitian ini digunakan pendekatan kualitatif untuk mengungkapkan permasalahan dalam lingkungan kantor kepala desa Cikolelet untuk pengumpulan data diambil melalui wawancara, pengamatan lokasi dan studi pustaka, serta metode pengembangan sistem yang digunakan yaitu SDLC (Software Development Life Cycle) yang merupakan kerangka kerja untuk perencanaan dan pengendalian pembuatan sistem informasi, bahasa pemrograman yang digunakan adalah PHP berbasis web dan MySql sebagai DBMS dengan pengujian menggunakan Black Box. Hasil dari pelaksanaan kegiatan penelitian ini bertujuan untuk membantu kemudahan proses bagaimana digitalisasi dokumen surat dan agenda dan menjadikan kantor kepala desa Cikolelet sebagai salah satu smart village dalam hal pengarsipan surat dan agenda.
\end{abstract}

Kata Kunci : Cikolelet, digitalisasi dokumen, surat dan agenda

\section{PENDAHULUAN}

Teknologi Informasi merupakan peran penting dalam menunjang kehidupan manusia pada saat ini kegiatan dilakukan hampir keseluruhan pada semua bidang menggunakannya, pemberian informasi haruslah tepat sasaran dan akurat sehingga tidak ada pihak yang merasakan dirugikan akibat dari hal tersebut. Pada tahun 2017 merupakan tahun pertumbuhan ekonomi global terbesar yang terjadi sejak tahun 2011. Hal ini disebabkan karena setiap industri manufaktur melakukan percepatan dan pertumbuhan produktivitasnya. Kemajuan pertumbuhan ekonomi dan industri yang terjadi tidak terlepas dari pengaruh kemajuan teknologi. Era teknologi yang saat ini dijalankan adalah pemberdayaan peran integrasi digital pada sektor industri yang selanjutnya dikenal sebagai Era 
Industri 4.0 (Suharman \& Murti, 2019). Cikolelet adalah desa yang berada di kecamatan Cinangka Kabupaten Serang, Banten, Indonesia yang pada saat ini menjadi desa wisata pada tahun 2018. Sesuai surat keputusan (SK) bupati, Dinas Pemuda Olahraga dan Pariwisata (Disporapar) dan organisasi perangkat daerah (OPD). Kementerian Pariwisata Republik Indonesia kembali memperkuat program pemberdayaan desa dengan pendekatan program desa wisata. Program ini mentargetkan terbentuknya 2000 desa wisata yang tersebar di seluruh Indonesia (Suprina, Rachman, \& Fitriana, 2019).

Dalam hal ini untuk meningkatkan perkembangan desa wisata Cikolelet terutama pada Kantor Kepala Desa Cikolelet salah satunya perihal manajemen dokumen surat dan agenda pada lingkungan kantor kepala desa Cikolelet yang belum terorganisir secara baik dalam pengelolaannya dimana bagian kesekertariatan Desa mengalami kesulitan. Salah satu proses yang dilakukan saat ini untuk melakukan pencarian informasi berdasarkan surat maupun agenda mengalami hambatan dalam masalah waktu sebaliknya aparatur desa dituntut agar dapat bekerja dengan cepat dalam melakukan semua aktivitas. Selain itu untuk melihat jadwal kegiatan ataupun surat kepala desa harus melalui berkas pada saat ini kegiatan penyimpanan tidak terstruktur pada penempatannya maka akan terjadi keterlambatan dalam pemberian informasi pada hal ini akan merugikan pihak yang bersangkutan dalam kegiatan pekerjaannya untuk melakukan pengurusan surat dan agenda. Penumpukan berkas yang dilakukan kesekretariatan saat ini tidak begitu aman karna mudahnya rusak kertas ataupun hilang.

Berdasarkan permasalahan yang dihadapi akan kebutuhan terhadap suatu aplikasi sistem dalam melakukan kegiatan pada kantor desa cikolelet terutama bagian kesekretariatan maka diperlukannya aplikasi sistem yang dapat membantu aparatur desa dalam pendataan surat, agenda dan diharapkan mengurangi penggunaan berkas hardcopy dan tempat penyimpanan.

Batasan dalam penelitian ini digunakan agar tidak terlalu luas maka dari itu ruang lingkup sebagai berikut penelitian berlokasi di Kantor Desa Cikolelet, penelitian ini mengenai Kantor Kepala
Desa Cikolelet bagian Kesekretariatan, penelitian ini hanya mencakup masalah surat dan agenda. Tujuan penelitian ini diambil berdasarkan permasalahan yang ada pada wilayah kantor Kepala Desa Cikolelet adalah sebagai berikut menjalankan salah satu industri revolusi 4.0 pada kantor kepala desa cikolelet pada bagian kesekretariatan, menunjang kegiatan aparatur desa dalam menanggani surat dan agenda, memudahkan dalam pengelolaan penyimpanan berkas surat (pengarsipan).

Target yang diharapkan dicapai setelah pelaksanaan kegiatan penelitian pembuatan aplikasi pada manajemen surat dan agenda kantor kepala Desa Cikolelet bagian kesekretariatan dapat melakukan manajemen surat dan agenda berdasarkan kategori sehingga menghemat waktu dalam pencarian berkas maupun keamanan dalam penyimpanan berkas.

\section{METODE}

Aplikasi manajemen surat dan agenda yang akan dilaksanakan pada Desa Cikolelet khususnya kantor kepala desa cikolelet, aplikasi ini membantu dalam pembuatan surat dan agenda serta mengatur tempat penyimpanannya sesuai dengan kategori yang telah ditentukan berdasarkan kegiatan yang akan dilaksanakan. Perancangan aplikasi ini akan dilakukan dalam beberapa tahapan meliputi bagaimana pengumpulan data dilakukan dan bagaimana perancangan aplikasi sistem surat dan agenda yang sesuai melalui tahapan seperti berikut.

\section{PENGUMPULAN DATA}

Observasi Pengumpulan data melalui metode observasi dilakukan dengan mengamati langsung di tempat pemantauan kantor kepala Desa Cikolelet pada bagian kesekretariatan. Pengamatan langsung memungkinkan didapatkannya data dan informasi secara realtime. Wawancara Pengumpulan data melalui metode wawancara dilakukan dengan mengajukan beberapa pertanyaan kepada kepala desa dan bagian kesekretariatan serta pengumpulan studi pustaka yang membahas tentang manajemen surat dan agenda.

Teknologi Informasi dan Komunikasi 132 


\section{PENGEMBANGAN SISTEM}

Metode pengembangan sistem dilakukan menggunakan sdlc karena model ini adalah model yang paling poluler dalam pengembangan sistem. Tahapan sebagai berikut.

\section{Communication}

Tahapan ini didapat dari hasil wawancara oleh pihak terkait kantor desa cikolelet, pertanyaan dari wawancara meliputi (permasalahan yang saat ini terjadi, dan dari pertanyaan tersebut nanti diusulkan antarmuka sistem, fitur dan fungsi aplikasi apa yang nanti akan dirancang serta dokumen pendukung).

\section{Planning}

Tahapan ini menjelaskan estimasi penjadwalan dari masing kegiatan perancangan sistem yang akan dilakukan selama 6 bulan.

\section{Modelling}

Tahapan ini menjelaskan rancangan antarmuka sistem aplikasi yang akan menggunakan front end framework bootstrap, bahasa pemrograman menggunakan PHP, Javascript dan MySql sebagai database yang akan digunakan serta pendukung lainnya sebagai text editor adalah visual studio code.

\section{Construction}

Tahapan ini akan dilakukan pengujian fitur dan fungsi pada aplikasi oleh pihak terkait yang akan mengunakan aplikasi sistem ini, yaitu dengan UAT (User Acceptence Test) Black Box testing.

\section{Deployment}

Tahapan ini akan dilakukan implementasi dari aplikasi sistem dan bagaimana pemeliharaan sistem dilakukan serta mengatasi jika terjadi sesuatu hal yang mengakibatkan error pada sistem dan akan dievaluasi pada 1 bulan ketika program dilaksanakan.

\section{HASIL DAN PEMBAHASAN 1. Analisa Berjalan}

Pada tahapan ini penelitian sudah melakukan wawancara terkait pihak desa, melakukan Analisa data dan perancangan sesuai dengan kebutuhan yang telah diberikan. berikut hasil Analisa dan perancangan.

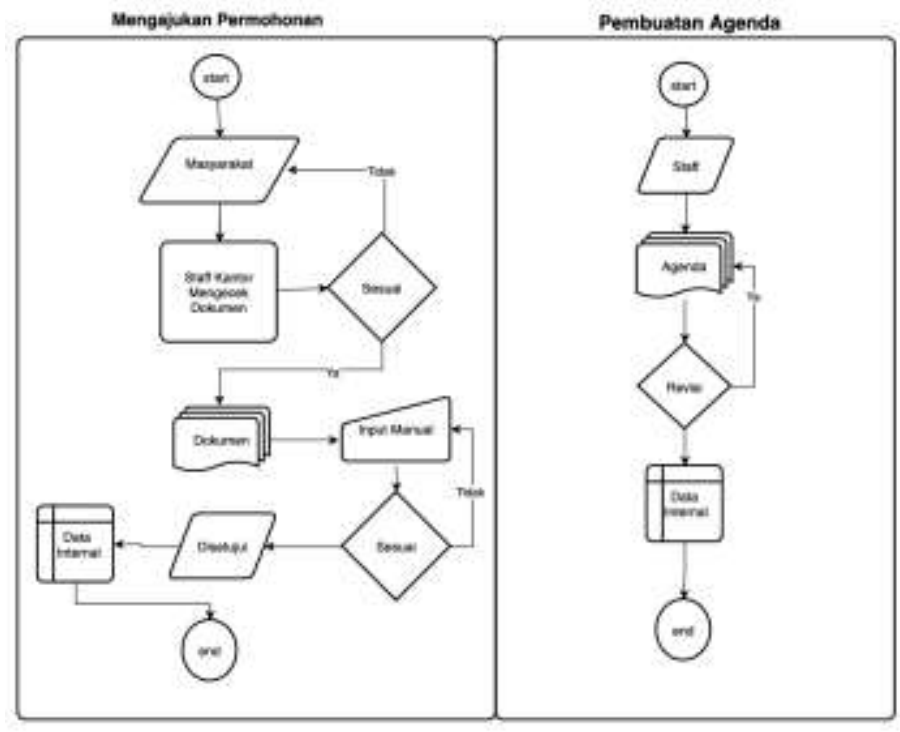

Gambar 1. Alur Analisa Berjalan

\section{ERD dan UseCase Usulan}

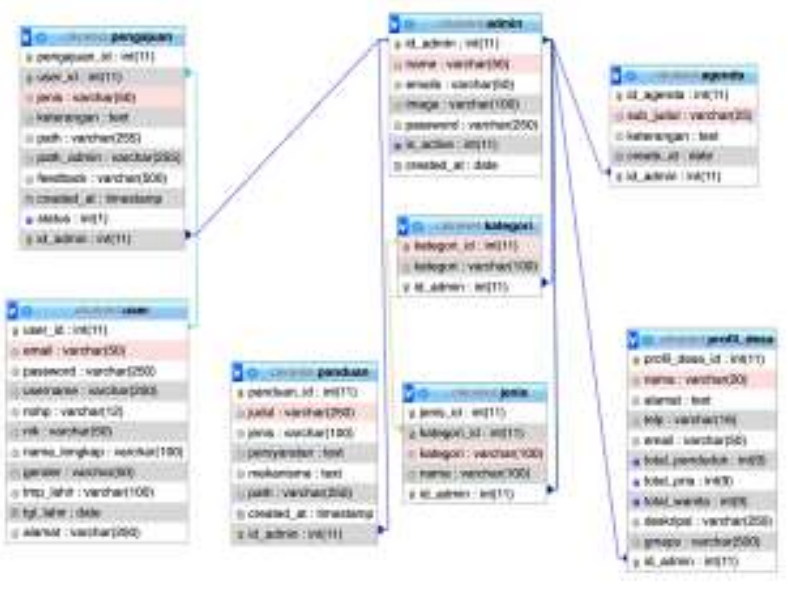

Gambar 2. ERD 


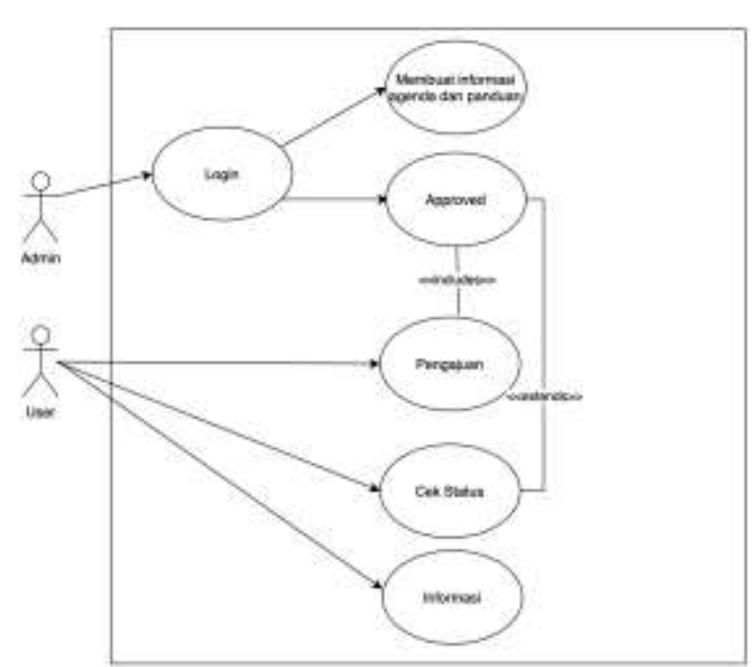

Gambar 3. Use Case

\section{PERANCANGAN}

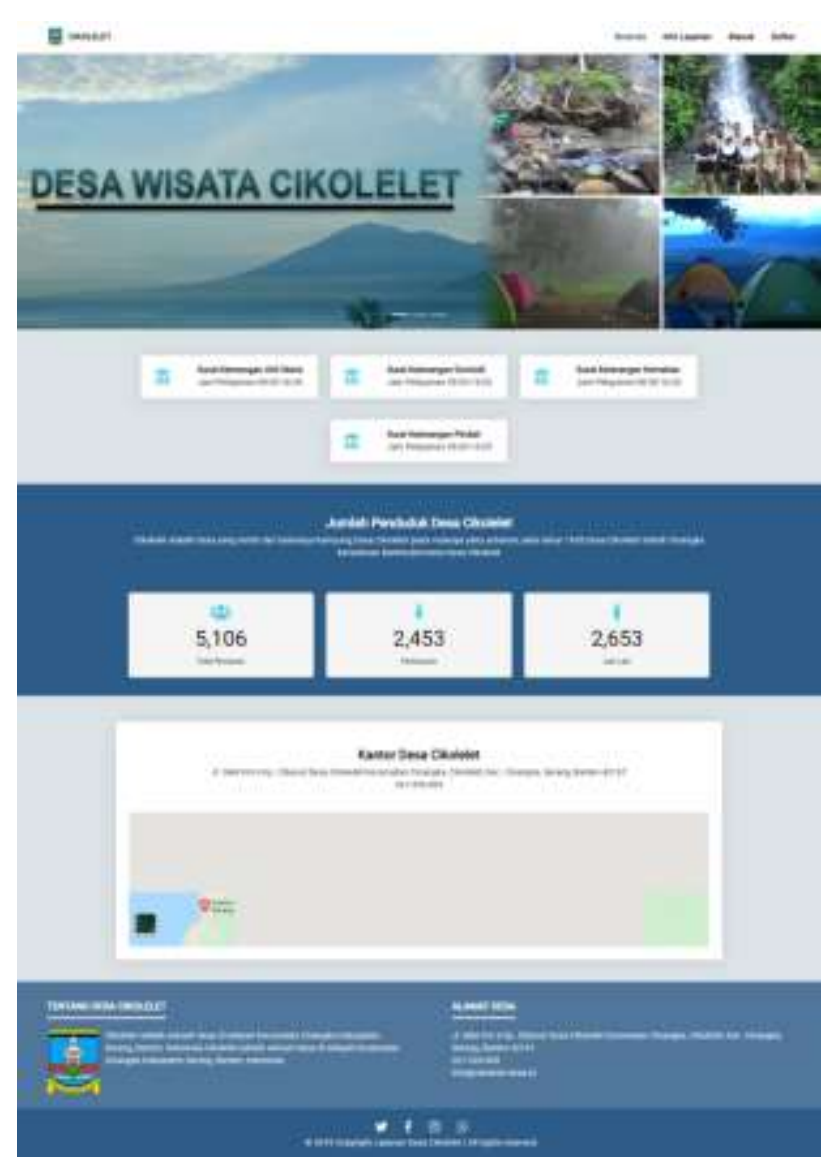

Gambar 4. Perancangan Web
Halaman Utama atau beranda adalah halaman awal yang akan muncul saat pertama kali membuka website. Informasi yag di sajikanadalah daftar layanan dan waktu operational, surat dan agenda mengenai informasi terkait desa cikolelet.

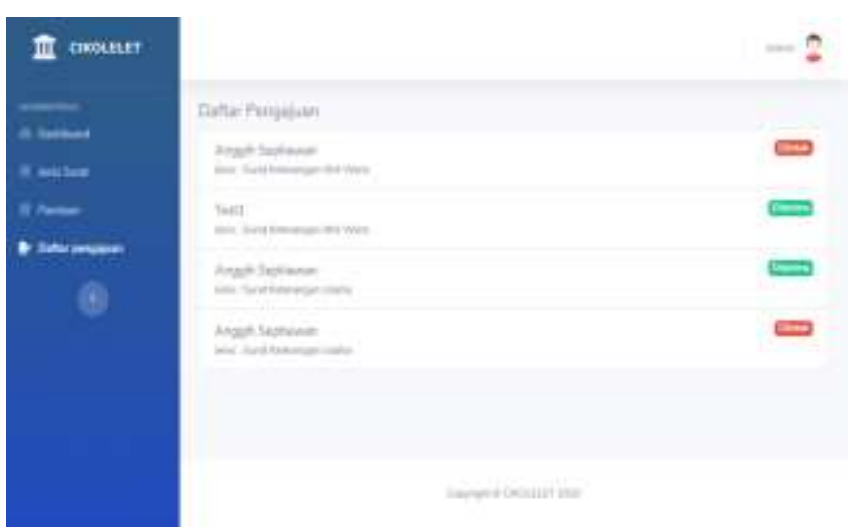

Gambar 5. Halaman Daftar Pengajuan

\section{IMPLEMENTASI}

Tahapan ini merupakan langkah yang dilakukan dalam implementasi pengujian sistem layanan yang diakses oleh user (warga cikolelet) dan Admin.

Tabel 1. Pengujian Sistem

\begin{tabular}{|l|c|}
\hline \multicolumn{1}{|c|}{ Item Pengujian } & Status \\
\hline Link setiap url & Valid \\
\hline Informasi web & Valid \\
\hline login & Valid \\
\hline CRUD & Valid \\
\hline Report & Valid \\
\hline
\end{tabular}

\section{KESIMPULAN}

Dengan Sistem Informasi Pelayanan Surat Desa Berbasis Web untuk memberikan solusi yang mana mempermudah mengenai pengajuan dan administrasi surat desa dan informasi terkait dengan agenda desa Cikolelet. Prosedur dan proses pengajuan menjadi lebih cepat dan mudah. Petugas desa dapat kemudahan management pengarsipan surat digital dan layanan yang lebih efisien dan efektif. Akan meningkatkan kinerja desa kepada layanan dan masyarakat desa.

Teknologi Informasi dan Komunikasi 


\section{UCAPAN TERIMAKASIH}

Terima kasih kepada Universitas Pradita dan Lembaga Penelitian dan Pengabdian Kepada Masyarakat (LPPM) Universitas Pradita, serta PkMCSR 2021.

\section{REFERENSI}

Gunawan, N. L., Suprianto, A., \& Maulana, Y. M. (2016). Rancang Bangun Aplikasi Manajemen Surat Berbasis Web Pada Dinas Perhubungan Kota Surabaya. Jsika Vol. 5, No. 7, 1-7.

Suprina, R., Rachman, A. F., \& Fitriana, R. (2019). Peningkatan Kapasitas Desa Wisata Cikolelet Melalui Program Pendampingan. Jurnal Pemberdayaan Pariwisat, 26-35.

Guntari, R., \& Setiawan, R. (2016). Rancang Bangun Aplikasi Pengelolaan Surat Di Desa Tanjung Kamuning. Jurnal Algoritma Sekolah Tinggi Teknologi Garut, 269-274.

Suharman, \& Murti, H. W. (2019). Kajian Industri 4.0 Untuk Penerapannya Di Indonesia. Jurnal Manajemen Industri Dan Logistik, 1-13.

Marliani, L. (2018). Definisi Administrasi Dalam Berbagai Sudut Pandang. Dinamika, 5(4), 17-21.

Suyitno. (2017). Analisis Penerapan Sistem Informasi Manajemen Dan Kompetensi Pegawai Serta Pengaruhnya Terhadap Kinerja Pegawai. Journal Of Business Administration, 1(2), 124-132.

Pressman, R. S. (2015). Rekayasa Perangkat Lunak: Pendekatan Praktisi Buku I. Yogyakarta: Andi.

Sembiring, V. A., Sari, I. M., \& Taviprawati, E. (2018). Pengembangan Potensi Desa Wisata Melalui Analisa Swot Di Desa Cikolelet, Serang, Banten. Seminar Nasional Hasil Pkm Universitas Pasundan, 1195-1204.
Saifudin, M. (2014). Rancang Bangun Sistem Digitalisasi Dokumen Menggunakan Metode Visible Watermark Di Kantor Urusan Agama (Kua) Kecamatan Sayung. Jurnal Mahasiswa Stekom Semarang, 1-9.

Nugrohoadhi, A. (2015). Pengorganisasian Dokumen Dalam Kegiatan Kepustakawan. Jurnal Khizanah Al-Hikmah, 3(1), 1-10. 